\title{
EFFECT OF SPANDEX DENIER OF WEFT CORE SPUN YARN ON PROPERTIES OF FINISHED STRETCH WOVEN FABRIC
}

\author{
Sunny Pannu 1, Meenakshi Ahirwar 2, Rishi Jamdigni ${ }^{3}$, B. K. Behera ${ }^{{ }^{2}}{ }^{\circ}$ \\ ${ }^{1}$ Department of U.I.E.T, Maharshi Dayanand University, Rohtak, Haryana 124001, India \\ 2 Department of Textile and Fibre Engineering, Indian Institute of Technology Delhi, India \\ 3 T.I.T\&S, Bhiwani, Haryana 127021, India
}

DOI: https://doi.org/10.29121/ijetmr.v7.i7.2020.720

Article Citation: Sunny Pannu, Meenakshi Ahirwar, Rishi Jamdigni, and B. K. Behera. (2020). EFFECT OF SPANDEX DENIER OF WEFT CORE SPUN YARN ON PROPERTIES OF FINISHED STRETCH WOVEN FABRIC. International Journal of Engineering Technologies and Management Research, 7(7), 21-32. https://doi.org/10.29121/ijetmr.v7 .i7.2020.720

Published Date: 15 July 2020

Keywords:

Spandex Denier

Stretch Properties

Physical Properties

Shrinkage

Core Spun Yarn

\section{ABSTRACT}

The woven fabrics containing cotton/spandex core spun yarns possesses very vital properties of stretch, recovery and thus shape retention from the view point of wearing comfort and garment appearance. Spandex present in the core of core spun yarn is the most essential performer behind these properties. An attempt is made in this research work to study the influence of changing spandex denier in core spun yarn on the stretch and functional properties of stretch woven fabrics. The sole objective of this study is to find out whether different stretch, shrinkage and physical properties of stretch woven fabrics depend upon changing spandex percentage achieved by means of change in spandex filament denier. It was observed that by increasing denier of spandex in core spun weft yarns the increase in weft shrinkage diminishes. Dual core weft with spandex provides good elongation percentage and recovery percentage. The fabric with higher denier spandex in yarn shows a decreasing total hand values trend for summer and winter. The results depicts that the fabrics have higher THV for winter suiting fabrics as compared to summer suiting thus are more suitable for the winter wear.

\section{INTRODUCTION}

Nowadays, proper fit and neat appearance of clothing plays a decisive role in its acceptance for mass consumption. The apparel fabric must possess a comfortable fit to the body in steady state and elasticity during body movement. These performances can be efficiently achieved by a fabric that has two special properties along with other required mechanical properties. Firstly, stretch properties to handle formability and body fitting and secondly, the recovery properties that deals with regaining body shape by the fabric after stretching. The evolution of elastomeric filament or spandex is among new inventions to enhance such stretch and recovery properties of the fabric. Thus important features like excellent elasticity with high degree of recovery and good shape retention can bring in to an apparel fabric by means of introducing elastomeric component in the fabric either as pure filament or by merging spandex filament with other textile fibers. This merging can be accomplished by various methods like core spinning, cover spinning, siro spinning and air twisting. Out of these, core spinning have become popular for producing stretch yarns suitable for knitting, weaving and other applications. In core spun yarn, there is one or many elastomeric filament/s in the center that forms core and this core is surrounded with other relatively less elastic staple fibers. This arrangement of fibers brings all the characteristics of sheath staple fiber along with the advantage of required stretch [1], [2], [3].

(C) 2020 The Author(s). This is an open access article distributed under the terms of the Creative Commons Attribution License, which permits unrestricted use, distribution, and reproduction in any medium, provided the original author and source are credited. 
Due to this gradual increase in demand of stretch woven fabrics by customers and manufacturer, many researchers have done studies on core spun yarns investigating the effect of a number of factors on which various properties of core spun stretch yarns and hence woven stretch fabrics depend. Ozdil [4] investigated denim stretch fabrics for performance properties and concluded that as the elastane content in the fabric increases, tensile and tearing strength decrease and fabrics become stiffer. It was also observed that as the elastane content in the fabric increases, the stretching and maximum stretching percentages increase, whereas the permanent stretch, bagging and permanent bagging values decrease. The outcomes of the tests advocate the benefits of adding elastane to fabrics and that also in an optimum amount.

Mourad et al. [2] reported an increasing trend in fabric contraction, maximum stretch, elastic recovery and elongation at break with increase in spandex rate in cotton plain woven fabrics containing different rates of elastane. On the other hand, fabric growth shows is a negative trend with increasing values of spandex rate. However, it is reported that more amount of elastane in fabric decreases its tensile strength, tear strength and air permeability. Qadir B et al. [5] have studied the effect of elastane denier on physical and stretch properties of stretch woven fabrics. They concluded that an increase in elastane percentage increases the tear strength and recovery percentage. However a decrease is observed in tensile strength of fabric. El-Ghezal et al. [6] performed experiments to study the effect of finishing process and the elastane percentage on the mechanical and elastic properties of stretch denim. The results revealed that, blazing and mercerization finishing results in relaxation in the weft direction that is evident by the shrinkage in fabric width, increase in areal density.

AL-ansary [7] carried out experiments on cotton stretch fabrics and outcomes revealed a remarkable effect of yarn spandex ratio on properties. The results indicate that increasing spandex ratio shows a positive relationship with fabric extensibility and air permeability. A negative relationship was observed among fabric tensile strength, shrinkage and growth of woven fabrics. Choudhary et al. [8] reported that the finishing type, weight and elastane content of stretch denim have a significant effect on its physical and stretch properties. The results revealed that incorporation of elastane lowers the breaking strength, air permeability, growth percentage and increases the breaking extension, stretch and recovery percentage of the fabric. Ertas et al. [9] reported that the effect of using dual-core weft is parallel to the effect of using single core weft thread. Finally it was stated that fabric construction in terms of weft density greatly affects the fabric width instead of elastane ratio.

Except one or two, the most researches are based on the varying elastane percentage of spandex or elastane in fabric by means of changing number of spandex weft. Here arises the need to study the influence of varying spandex percent in yarn itself on the stretch and functional properties of stretch woven fabrics that whether the different stretch, shrinkage and physical properties of stretch woven fabrics depend upon changing spandex percentage achieved by means of change in spandex filament denier.

\section{MATERIALS AND METHODS}

\subsection{MATERIALS}

In this study, woven fabric was prepared in a weaving mill under controlled manufacturing conditions. Five 3/1 $\mathrm{S}$ twill structured stretch woven fabrics were prepared with varying spandex content by means of different spandex Denier/content in weft yarn. For warp, 20/1 Ne conventional $100 \%$ cotton yarns with thread density of 108 yarns/inch were used. For weft, 16/1 Ne cotton/spandex core spun yarns with thread density 56 yarns/inch were used. The major parameter investigated in this experiment is the varying spandex content in fabric i.e. $1 \%, 1.5 \%$, $2 \%, 2.5 \%, 3 \%$ obtained by using different spandex deniers $40,70,105,140$, Dual core respectively in weft core spun yarn. All samples were woven on air-jet looms with keeping same rpm, reed and reed space for all the samples. The fabric codes with description are listed in Table 1. The eight replicate samples were prepared for each of the five fabrics for results authenticity and accuracy.

Table 1: Fabric codes with description

\begin{tabular}{|c|c|c|c|}
\hline Sr. No. & Fabric code & Spandex filament denier in weft core & Spandex content in fabric \\
\hline 1 & F 40 & 40 & $1 \%$ \\
\hline 2 & F 70 & 70 & $1.5 \%$ \\
\hline 3 & F 105 & 105 & $2 \%$ \\
\hline
\end{tabular}


Sunny Pannu, Meenakshi Ahirwar, Rishi Jamdigni, and B. K. Behera

\begin{tabular}{|c|c|c|c|}
\hline 4 & F 140 & 140 & $2.5 \%$ \\
\hline 5 & F DC & Two filaments of 70 D each & $3 \%$ \\
\hline
\end{tabular}

\subsection{METHODOLOGY}

\subsubsection{PROCESS SEQUENCE}

The grey fabrics were processed according to the following processing route with the standard process parameters used for commercial production.

Grey fabric $\rightarrow$ Grey wash $\rightarrow$ Heat Set $\rightarrow$ Pretreatment $\rightarrow$ Mercerization $\rightarrow$ Peach $\rightarrow$ Wash $\rightarrow$ Dry pad $\rightarrow$ Pad steam $\rightarrow$ Finish $\rightarrow$ Dry

\subsubsection{FABRIC TESTING}

In the present study, the fabric samples were tested for important mechanical properties including fabric count, fabric width, fabric boil-off \& residual shrinkage and functional properties of fabric such as tensile strength, tear strength, fabric crease recovery, fabric wrinkle recovery and drape. Stretch properties of fabric including elongation, growth and recovery were also evaluated. These tests were carried out after each processing stage. So, the effect of both the finishing process and the spandex percentage on the fabric properties may be revealed at once. Eight replicate samples of five fabrics as given in Table 1 were used for the study and an average of three observations was taken for each sample.

\subsubsection{DETERMINATION OF WRINKLE RECOVERY}

Appearance method was used to determine the wrinkle recovery of fabrics according to AATCC 128 . The sample size was $6 * 11$ inch. Under standard atmospheric conditions the sample fabrics were induced to a large number of random wrinkles intentionally. A load of 3500 grams was used for 20 min to wrinkle the fabrics. The fabrics were conditioned again after wrinkling for 24 hour and rated for appearance by three trained observers. The ratings were given to the samples by comparing them with AATCC wrinkle recovery replicas standard samples.

\subsubsection{DETERMINATION OF DIMENSIONAL PROPERTIES}

The dimensional properties of the fabrics were determined after the different processing methods. The finish width of the fabric was measured using ASTM D 3774-96. The weight was measured using ASTM D 3776-2002. The finish EPI and PPI were measured using ASTM D 3775-2003.

\subsubsection{DETERMINATION OF CREASE RECOVERY ANGLE}

Shirley crease recovery tester was used to determine the crease recovery angle. A $40 \times 15 \mathrm{~mm}$ specimen size was used. For each fabric, six specimens were cut in each warp and weft direction. Each test specimen was folded face to face and creased under $2 \mathrm{~kg}$ weight for $1 \mathrm{~min}$ and then allowed to recover from creasing for $1 \mathrm{~min}$. Out of six, three specimens were tested with folding face to face of sample and three with folding back to back creasing. Finally, the average of six values of warp-wise and weft-wise crease recovery angle was measured [10] using the standard IS 4681 - 1968.

\subsubsection{DETERMINATION OF TEAR STRENGTH}

The falling-pendulum type (Elmendorf) tearing tester was used to determine the fabric tear strength according to the ASTM D1424 standard. The sample size was 100*63 mm. Tear force used was $33.77 \mathrm{~N}$. The unit of tear strength was Newton. Five reading were taken in warp direction and five in weft direction. The average of warp and weft samples was taken. 


\subsubsection{DETERMINATION OF STRETCH PROPERTIES}

According to ASTM standard D3107-07, fabric's stretch properties include 'fabric stretch under a specified tension', 'fabric growth after a specified tension', 'fabric growth after stretching to a specified extension', and 'fabric recovery'.

The three pairs of samples with dimension $65 \mathrm{~mm} \times 560 \mathrm{~mm}$ were taken with long dimension parallel to the test direction. Benchmarks were placed on each sample $250 \mathrm{~mm}$ apart. The test specimen was clamped in the testing apparatus with a hanging load of $1.8 \mathrm{~kg}$ for stretching. The distance between the benchmarks was measured after 10 sec. The load and lower clamp of apparatus were removed to allow the sample to recover.

Fabric stretch is evaluated as the measured resulting length difference between the benchmarks on the test specimen before and under the applied tension after a specified time. Fabric growth is evaluated as the measured resulting length difference between the benchmarks on the test specimen before the applied tension and after relaxation for a specified time. Fabric recovery is evaluated as the percentage of fabric growth recovered with respect to the fabric growth after applied tension.

Then the fabric stretching (eq. i), fabric growth (eq. ii) and elastic recovery (eq. iii) of the fabrics were calculated:

Fabric stretching $(\%)=100 *(\mathrm{~B}-\mathrm{A}) / \mathrm{A}$

Fabric growth $(\%)=100 *(\mathrm{C}-\mathrm{A}) / \mathrm{A}$

Elastic recovery $(\%)=100 *(B-C) /(B-A)$

Where, A- the distance between the upper and bottom benchmark on the test specimen (250 mm), B- The distance between the upper and bottom benchmark after $10 \mathrm{sec}$ of loading the test specimen (mm) and C- The distance between the upper and bottom benchmark after 1-hour relaxation.

\subsubsection{DETERMINATION OF TENSILE PROPERTIES}

ASTM D 5035 - 06 was used to determine the tensile strength test of fabrics. The grab test evaluates breaking force as the maximum force applied to the fabric sample to rupture it. The samples were tested with a loading rate of $300 \mathrm{~mm} / \mathrm{min}$. Specimen size of $100 \mathrm{~mm} \times 150 \mathrm{~mm}$ was taken with long direction parallel to direction of test. The $75 \mathrm{~mm}$ gauge length is fixed in apparatus. Total five samples were tested each for warp and weft directions.

\subsubsection{DETERMINATION OF FABRIC HAND}

The sixteen low stress mechanical properties of the fabrics were measured by using the Kawabata Evaluation System (KES). Tensile and shear, bending, compression, and surface properties were evaluated using KES-FB1, KESFB2, KES-FB3, and KES-FB4 instruments respectively [11]. The fabric sample size was $20 * 20 \mathrm{~cm}$. For each sample ten readings were measured both in wrap and weft directions. The Kawabata set of equations were used to evaluate the primary hand values like stiffness, smoothness, crispness etc. and the total hand values were estimated using standard hand equation prescribed by Kawabata for summer and winter suiting garments. The primary hand value and the total hand value obtained were in a scale of 0-10 and 0-5 respectively.

\subsubsection{DETERMINATION OF FABRIC DRAPE}

Cusick drapemeter was used to determine the drape of each fabric sample. The drape coefficient was calculated by using this method. A circular test specimen of diameter $30 \mathrm{~cm}$ was used in the measurement. Two specimens were tested for each sample and from both face and back sides. An average of four readings was taken.

\section{RESULTS AND DISCUSSION}

The woven stretch fabric samples with different spandex content were evaluated for thread count (EPI, PPI), fabric weight, width, shrinkage, growth, recovery, tensile \& tear strength, crease \& wrinkle recovery and drape. The results were analyzed and presented in Figure 1-12. 


\subsection{EFFECT OF SPANDEX CONTENT ON THREAD COUNT}

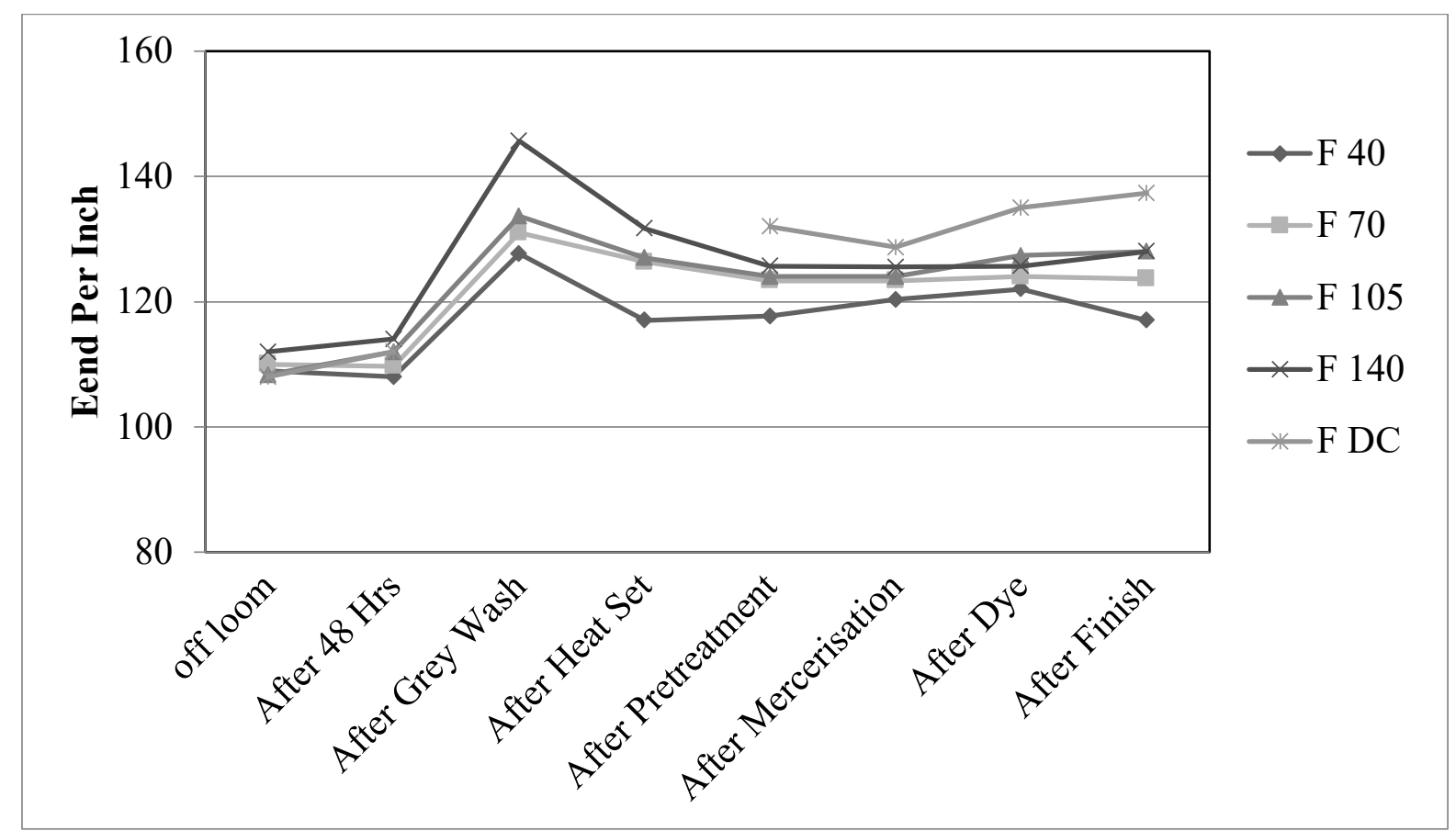

Figure 1: Effect of various treatments on EPI of samples with different spandex content

Figure 1 shows an overall increase in warp density of stretch woven fabric containing cotton/spandex core spun yarn in weft after wet processing and finishing. During processing, the fibers contained in yarn tend to relax and finally get stable in a new position with lower energy level. This results in a change and in most cases increase in thread density. This increment in number of yarns in unit length of fabric is reported more prominent in case of fabrics with elastane [4], [12]. As far as the effect of spandex content in weft yarn is concerned, the warp density increases with spandex amount in weft yarn. However, the increment is very little.

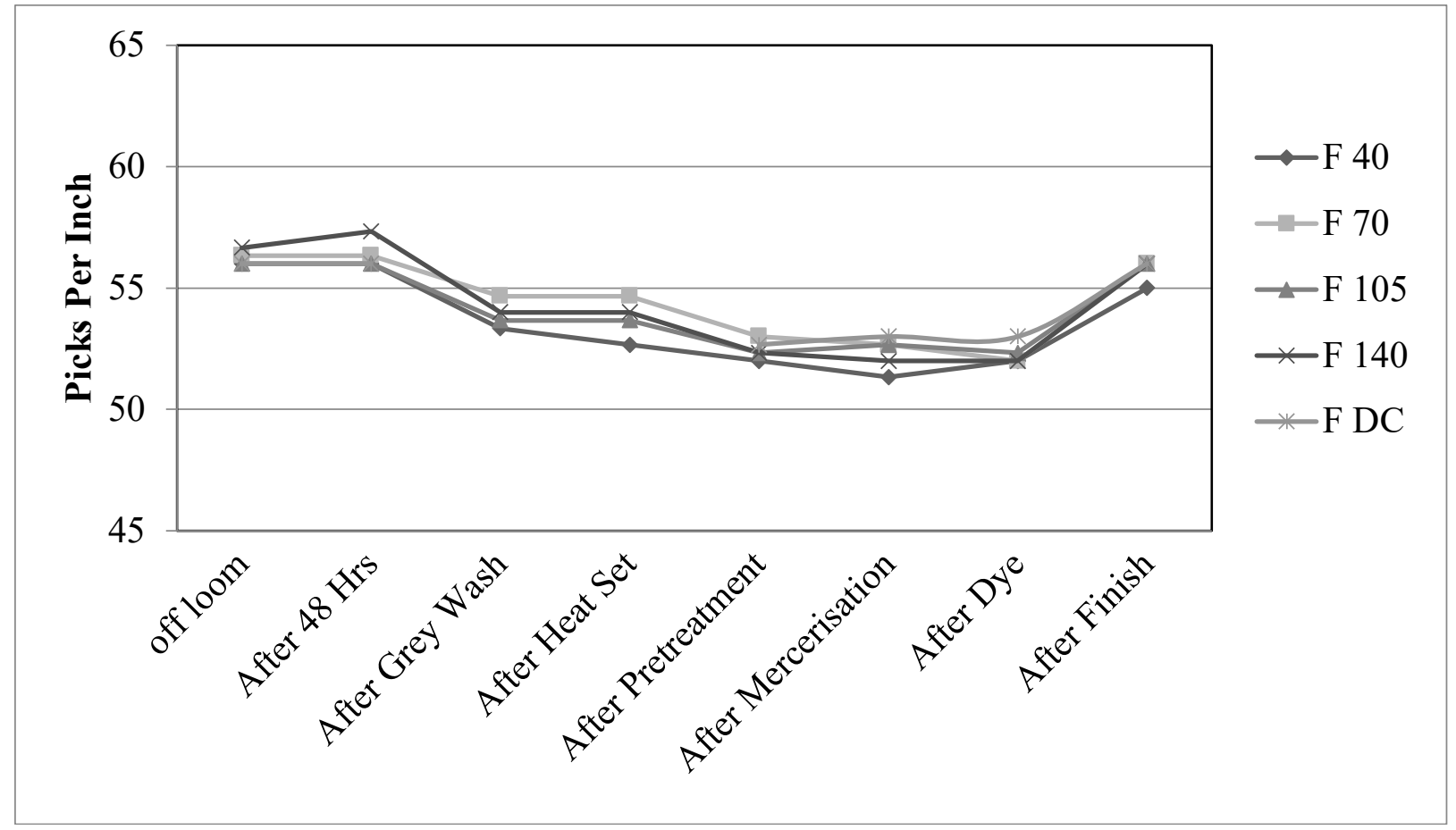

Figure 2: Effect of various treatments on PPI of samples with different spandex content 


\subsection{EFFECT OF SPANDEX CONTENT ON FABRIC AREAL DENSITY}

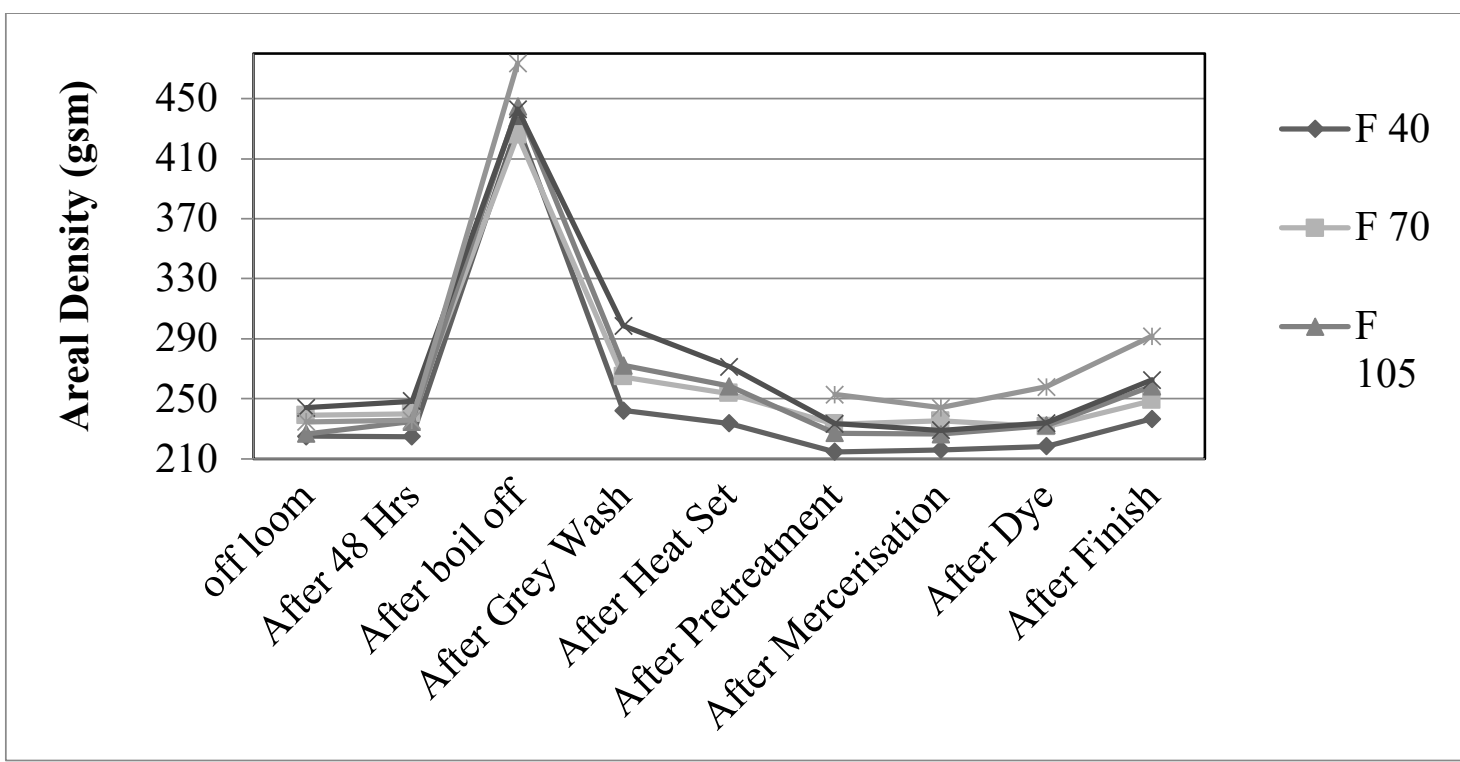

Figure 3: Effect of various treatments on GSM of samples with different spandex content

Fig. 2 indicates that there is no significant change in PPI among the samples due to the processing and change in spandex content in weft yarn.

The effect of spandex denier in core spun weft yarn on fabric areal density (GSM) is shown in Fig. 3. The increasing spandex denier increases the areal density (GSM) of the final finished fabrics. The increase may be attributed to increasing spandex percentage at higher spandex denier in core spun yarn. The literature advocates the generation of higher retraction force by higher denier spandex in yarn. This results in off loom fabric contraction along the weft direction [5].

\subsection{EFFECT OF SPANDEX CONTENT ON FABRIC WIDTH}

Fig. 4 shows a decreasing trend in fabric width due to increasing spandex content in weft yarn. The reason may be the fact that weft yarns crimp exerts a tension on the yarn in weft direction. This results in the fabric contraction in width. This behavior is more prominent in case of stretch fabrics containing spandex. The effect is further enhanced with the increasing amount of spandex denier in weft yarn results in reduction in width [2].

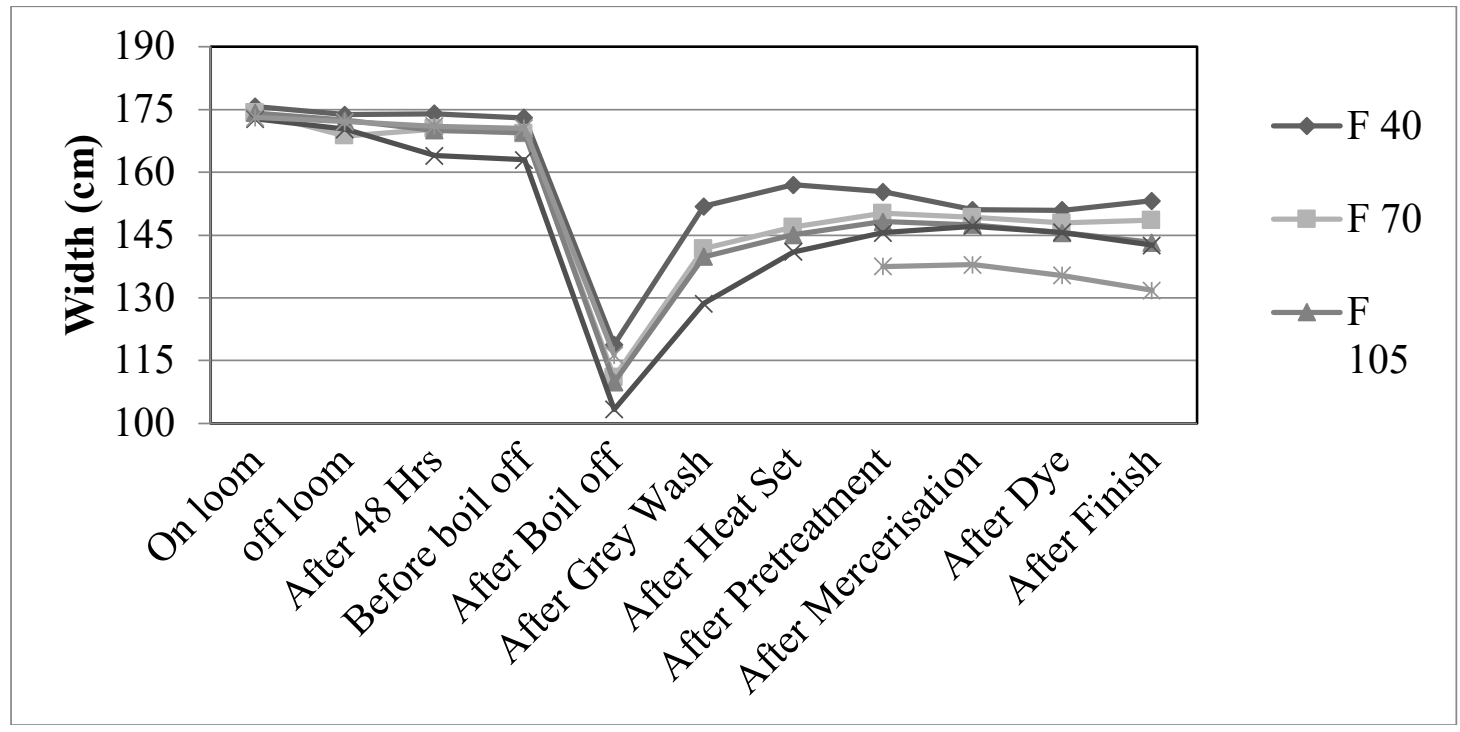

Figure 4: Effect of various treatments on width of samples with different spandex content International Journal of Engineering Technologies and Management Research 


\subsection{EFFECT OF SPANDEX CONTENT ON FABRIC EXTENSION, RECOVERY AND SHRINKAGE}

Elongation and recovery are the properties of prime importance for a fabric in view of the comfortable wearing and good aesthetics provided by that fabric in a garment. These properties even become more critical in case of woven stretch fabrics containing spandex. In such fabrics, stretch or extension comes from the inherent property of spandex filament to extend up to 300 to $700 \%$. The limit of this extensibility is dictated by the amount of spandex incorporated in yarn and hence in fabric [3]. The previous researches advocates the fact that fabric stretch-ability increases by increasing amount of spandex in yarn. This behavior can be attributed to the generation of higher retraction force by higher denier spandex in weft yarn. This results in off loom fabric contraction along the weft direction. Among stretchable fabrics, a fabric having higher contraction is considered more stretchable than that having less contraction [5].

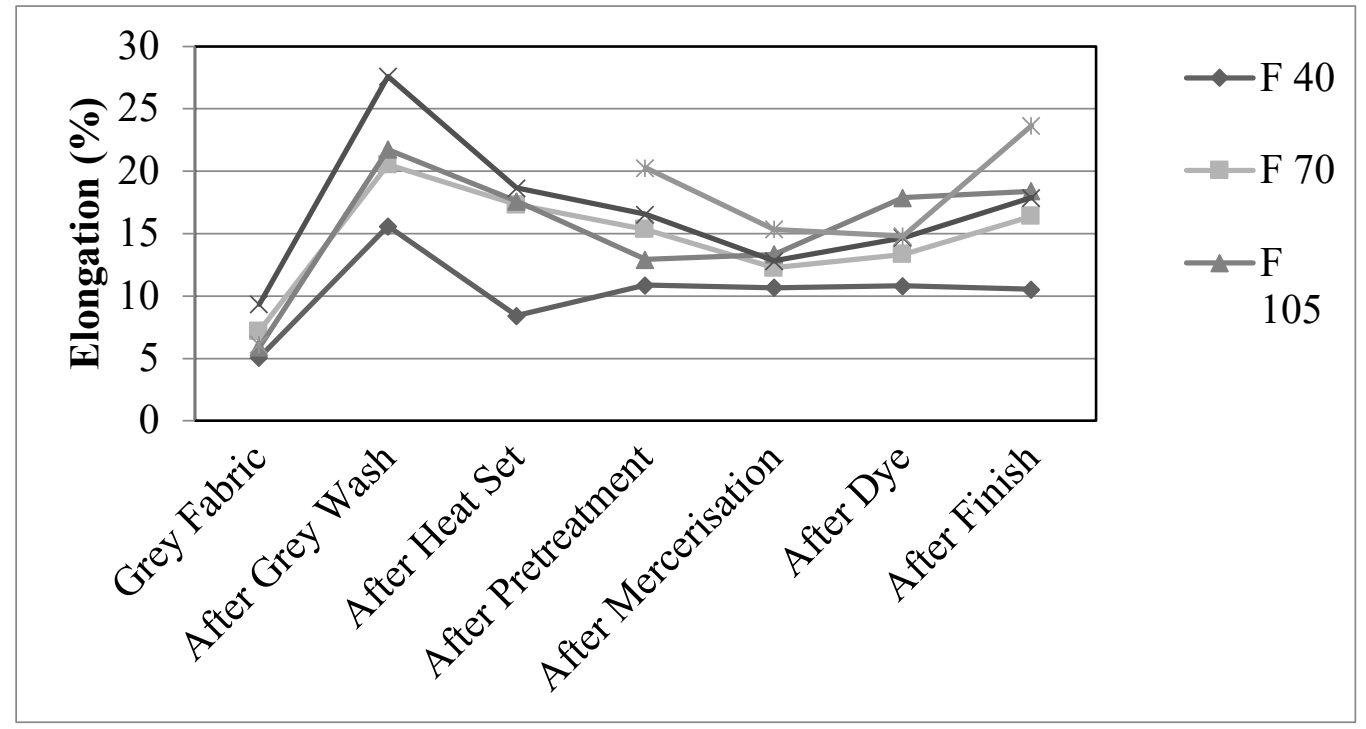

Figure 5: Effect of various treatments on elongation of samples with different spandex content

In present study also, the fabric containing higher amount of spandex in weft yarns makes the fabric more contracted in width due to more retraction forces and hence results in a higher elongation \% respectively. Similar trends are shown by recovery \%. The reason being the spring like behavior of spandex filament that exerts force on yarn to return to its original dimensions after stretching [2]. The findings of elongation and recovery are depicted in Fig. 5 and 6 respectively.

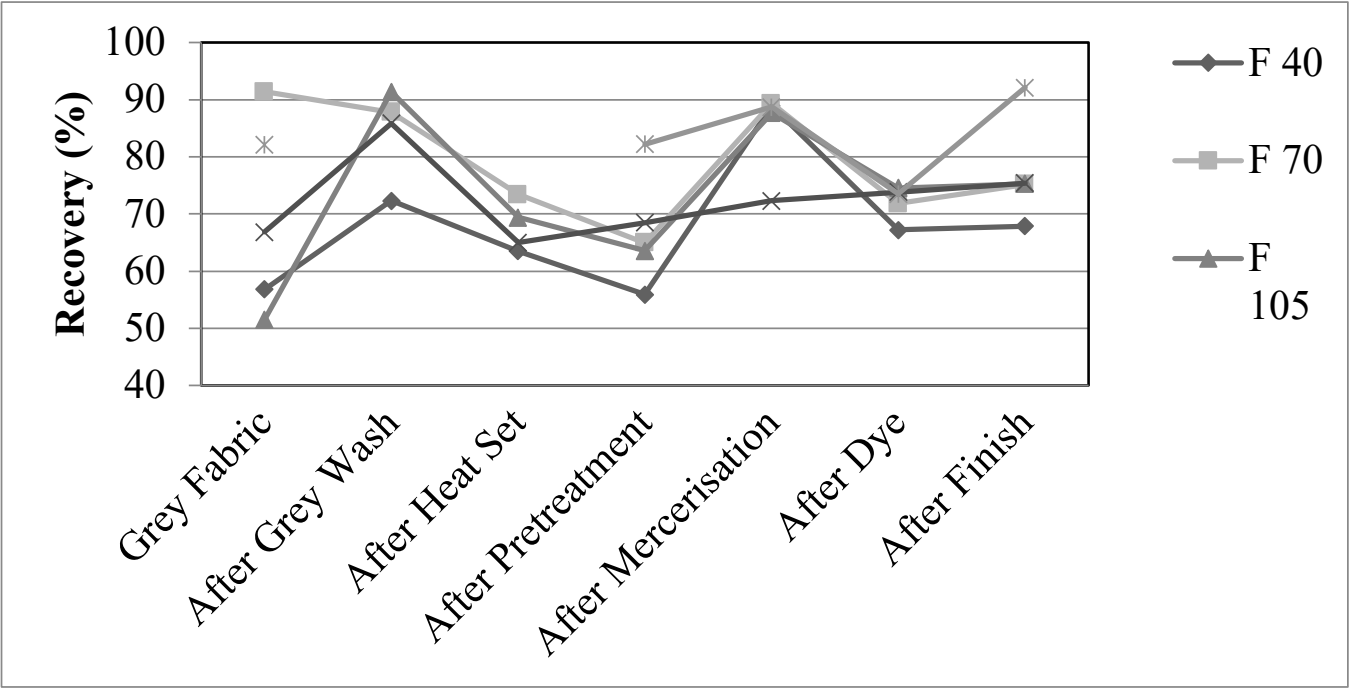

Figure 6: Effect of various treatments on recovery of samples with different spandex content 


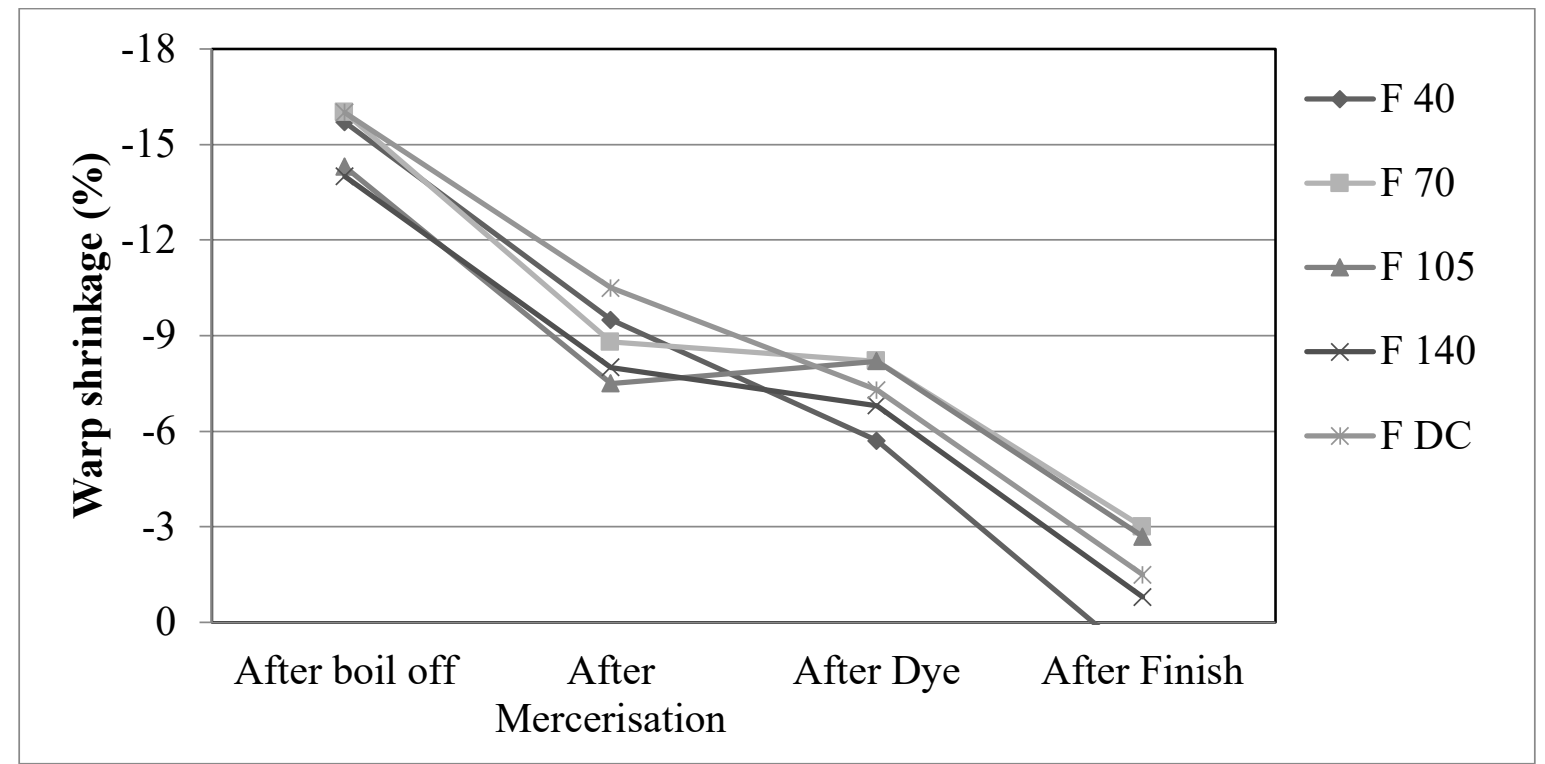

Figure 7: Effect of various treatments on warp shrinkage of samples with different spandex content

Fig. 7 and 8 depicts the shrinkage behavior of stretch fabrics warp wise and weft wise. There is an overall reduction in shrinkage percentage in all the samples due to processes of pretreatment, dyeing and final finish. In stretch fabrics with stretch only in weft direction, wet treatment results in remarkable width shrinkage due to release of temporary tension in yarns providing more space to spandex to stretch under tension. This relaxation indicates a decrease in weft shrinkage [2],[13]. After heat set, the spandex filament is fixed at more relaxed stage thus leaving a fabric with less potential to shrink further widthwise. After finish, a no significant change can be observed in the weft shrinkage value as an effect of changing spandex percentage in weft yarn. This possibly may be due to the structural jamming of the fabric as an influence of higher spandex denier.

Shrinkage is observed in warp direction also but lesser than weft direction. There can be seen a gradual decrease in warp shrinkage from grey fabric to final finish. The possible reason for initial shrinkage is the relaxation of temporary tensions in the yarn on encounter with water during processing. Previous studies found that the increasing spandex content results in an increase in relaxation shrinkage width wise. Due to this width wise shrinkage, the warp yarns come closer to each other thus increasing the frictional force between warp yarns, resulting in progressive shrinkage in the warp direction [14].

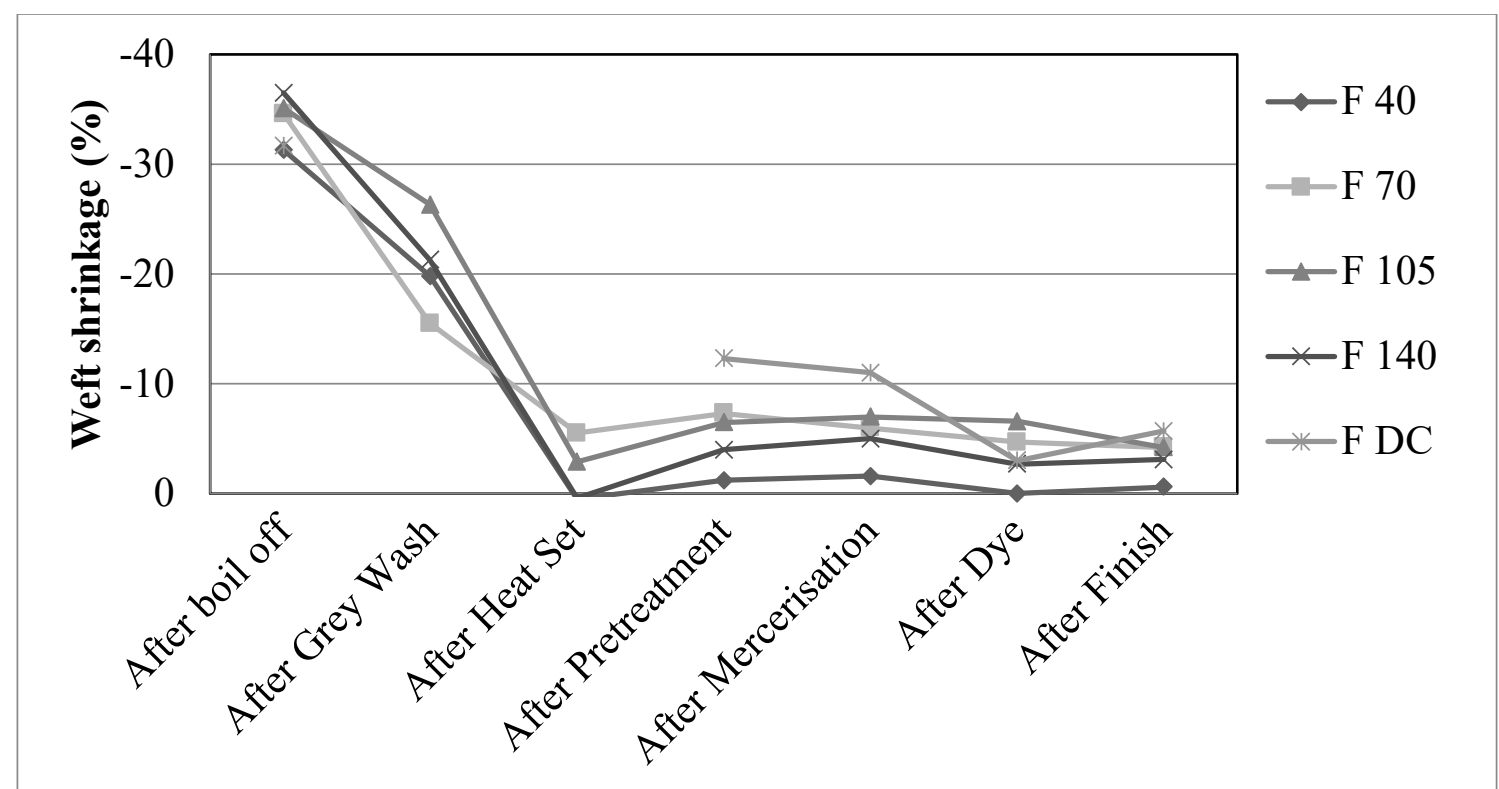

Figure 8: Effect of various treatments on weft shrinkage of samples with different spandex content 


\subsection{EFFECT OF SPANDEX CONTENT ON TENSILE STRENGTH OF THE FABRIC}

Tensile strength is an important parameter of a fabric that dictates its durability and quality. In case of stretch woven fabrics, many researchers established a negative relationship between tensile and amount of spandex or elastane in weft yarn of fabric [4], [5], [6], [7], [8]. In Fig. 9, the result outcomes of tensile properties have been represented after final finish. It can be observed that tensile strength of weft yarns is lesser than warp yarns. This may be due to the lower tenacity of spandex filaments compared to pure cotton fibers. The same count yarns with lesser spandex (\%) contain more amounts of cotton fibers give a higher tensile strength than yarns containing more spandex [5]. In contrary to the above mentioned researches, the results of the present study show an increase in tensile strength in warp and weft direction with increasing spandex denier in weft yarn [9],[14]. Though, this difference in tensile strength in weft direction is not significant among the samples. The reason behind this behavior may possibly be the increase in areal density a result of progressive shrinkage in the fabric from grey state up to finishing. As fabric weight increases, the breaking strength increases in both warp and weft directions [8].

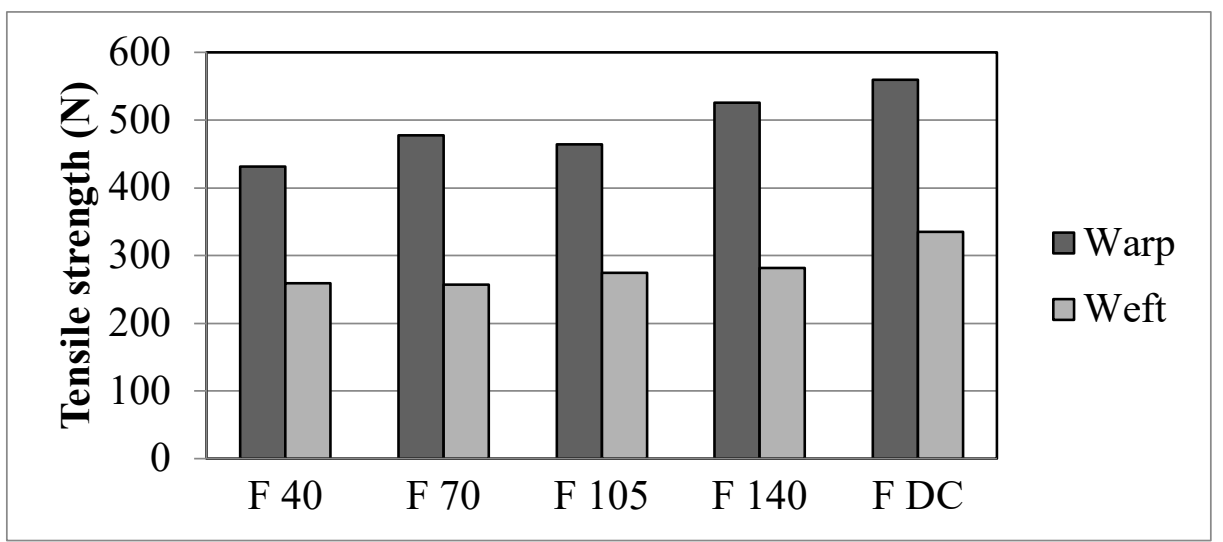

Figure 9: Effect of different spandex content on tensile strength (warp and weft wise)

Similar to tensile, tear strength of fabric also contributes to the total useable life and quality of a fabric. Technically, the tearing strength is the amount of ease with which yarns perpendicular to tearing force can be torn apart by the tearing force. During this the yarn slippage occurs in the fabric resulting in the closeness of yarns at tear point to resist tearing. This yarn slippage is reported to be better in case of fabrics woven with higher amount of spandex percentage in yarns. Hence, fabric with higher spandex denier should possess higher values of tearing strength [5]. As shown in Fig. 10, the experiment outcomes show a similar trend in tear strength in warp direction as discussed above. However, in weft direction, the tear strength values tend to increase along with increasing elastane denier in weft core spun yarns. The reason for this behavior may be the fact that during processing and finishing of fabrics containing elastane in weft, movement of the warp threads diminishes due to the elastane presence in weft. As the fabric become tighter, it will require lesser force to tear. However, this difference in tear strength in weft direction is not significant among the samples except sample containing dual core.

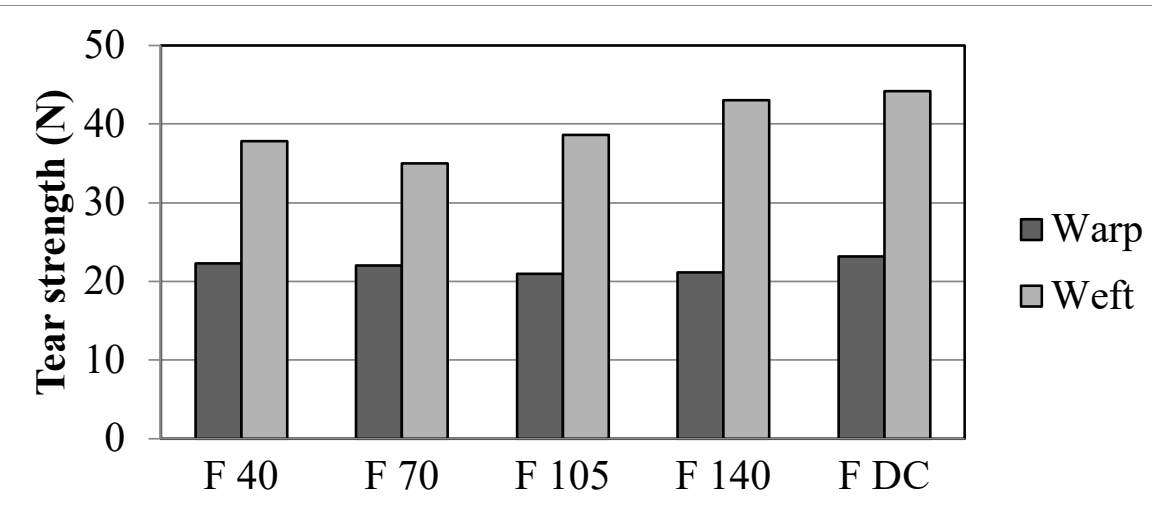

Figure 10: Effect of different spandex content on tearing strength (warp and weft wise) 


\subsection{ROLE OF SPANDEX CONTENT ON FABRIC CREASE RECOVERY ANGLE AND DRAPE COEFFICIENT}

The Fig. 11 shows the crease recovery angle for face and back in warp and weft directions for five object samples. The results show higher crease recovery angle for weft yarns compared to warp yarns. This is due to the incorporation of spandex filament in weft yarns that results in a more flexible yarn than yarn without spandex. In weft direction, more crease recovery angle can be observed for samples having more spandex content. The results are obvious as the increasing amount of spandex filament keeping final yarn count same makes the yarn softer and flexible. This increasing content of spandex in weft yarns pulls the warp yarns closer leaving a little space for yarn movement during folding. This possibly may be reason for decreasing crease recovery angle in face and back of warp yarns.

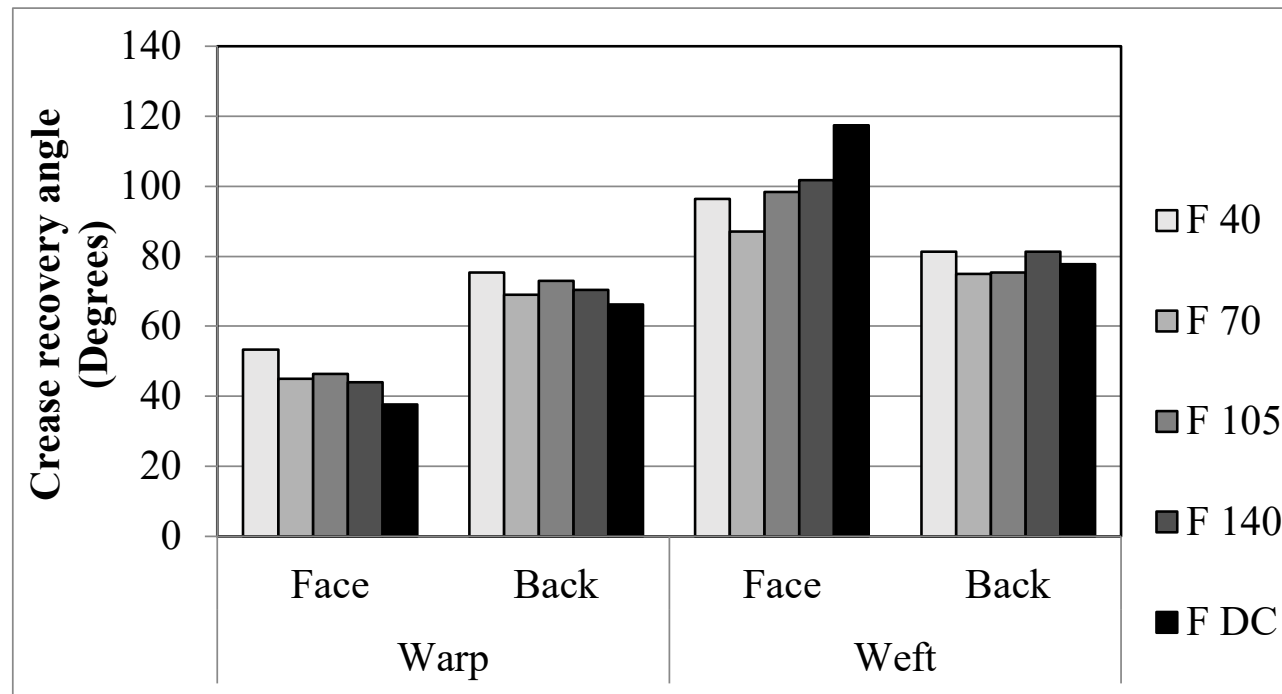

Figure 11: Effect of different spandex content on CRA (warp and weft wise)

Fabrics may get wrinkled during wearing and handling during laundering, tumble drying etc. The recovery from these wrinkles is one of the desirable characteristic of fabric as far as aesthetics appearance of the garment is concerned. As per previous researches, the wrinkle recovery majorly depends upon the fabric construction and fiber content. In case of spandex as fiber content, it has relatively good wrinkle recovery [14]. In present study, all five twill woven fabric samples with different spandex content show relatively similar behavior for wrinkle recovery. Samples have satisfactory wrinkle recovery rating will no significant difference among different spandex fiber content. The result outcomes of wrinkle recovery test and drape are shown in Table 2. As drape is the deformation in freely hanging fabric under gravitational force, it is in a strong positive relationship with fabric weight. In present experiment, the increasing spandex content in successive samples makes the fabric more compact and hence heavier. Thus the value of drape coefficient shows an increasing trend with increasing spandex denier in weft yarn.

Table 2: Test results for wrinkle recovery and drape

\begin{tabular}{|c|c|c|c|c|}
\hline \multirow{3}{*}{ Code } & \multicolumn{3}{|c|}{ Wrinkle Recovery Rating } & \multirow{2}{*}{ Drape coefficient } \\
\cline { 2 - 4 } & Observer A & Observer B & Observer C & \\
\hline \multirow{4}{*}{ F 40 } & 2 & 2 & 2 & \multirow{3}{*}{52.2} \\
\cline { 2 - 4 } & 2 & 2 & 2 & \multirow{3}{*}{55.7} \\
\cline { 2 - 4 } F 70 & 2 & 2 & 2 & \\
\cline { 2 - 4 } & 2 & 2 & 2 & \\
\cline { 2 - 4 } & 2 & 2 & 2 & \\
\hline & 2 & 2 & 2 & \\
\hline
\end{tabular}




\begin{tabular}{|c|c|c|c|c|}
\hline F 105 & 2 & 2 & 2 & \multirow{2}{*}{60.2} \\
\hline \multirow{3}{*}{ F 140 } & 2 & 2 & 2 & \multirow{3}{*}{59.3} \\
\cline { 2 - 4 } & 2 & 2 & 2 & \\
\cline { 2 - 4 } & 2 & 2 & 2 & \multirow{2}{*}{74} \\
\hline \multirow{3}{*}{ F DC } & 2 & 2 & 2 & \\
\cline { 2 - 4 } & 2 & 2 & 2 & \\
\cline { 2 - 4 } & 2 & 2 & & \\
\hline
\end{tabular}

\subsection{EFFECT OF SPANDEX CONTENT ON FABRIC HAND}

Fabric hand is the ultimate performance indicator of an apparel material. The hand value is not only material and structure specific; it also depends on applications and weather conditions. Fig. 12 shows the results of KES evaluation of the five object samples in view of the summer and winter suiting applications. The THV values indicate a decreasing trend with increasing spandex content in yarn except of 140 denier spandex yarn. All the five samples exhibit very low values of THV for summers and hence found unsuitable for summer suiting and fits well for winters (as shown by their Total Hand Values).

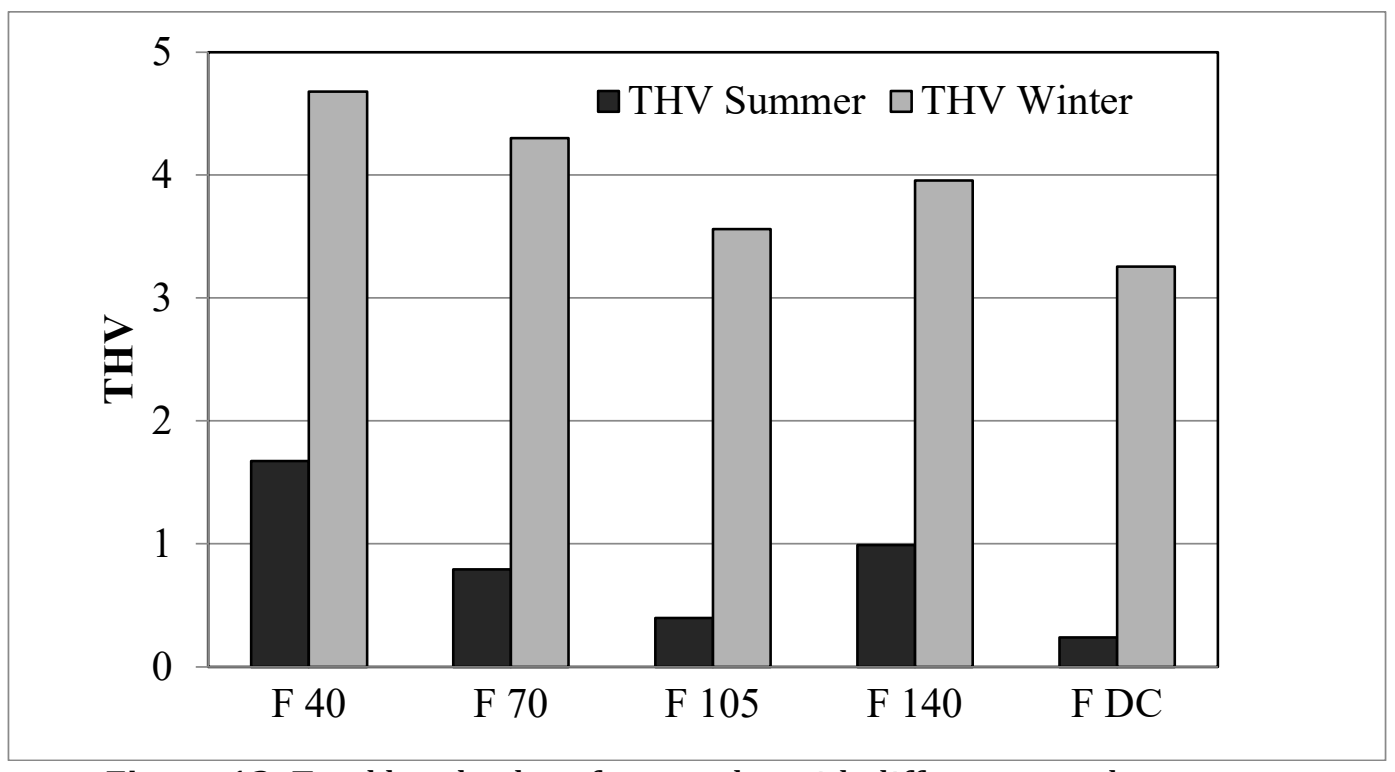

Figure 12: Total hand values for samples with different spandex content

\section{CONCLUSIONS AND RECOMMENDATIONS}

The aim of this part of the research was to calibrate spandex specifications (denier) as per the effect on the extension and performance characteristics of woven stretch fabric. It was concluded that by increasing denier of spandex in core spun weft yarns total spandex percentage of fabric increases. More retraction forces act in width wise direction resulting in more fabric contraction. This ultimately results in increased thread density, increased areal density and a reduction in fabric width. As fabric contracts more width wise, its stretch potential and recovery increase in this direction. An increment in weft shrinkage, tensile and tear strength was also observed. However, at much higher denier values of spandex, the increase in weft shrinkage diminishes. This is possibly due to the structural jamming of the fabric as a result of higher contraction. Dual core weft with spandex provides good elongation percentage and recovery percentage.

In case of fabric hand values, the fabric with higher denier spandex in yarn shows a decreasing total hand values for summer. All the five samples exhibit very low values of THV for summers and hence found unsuitable for summer suiting and hence fit well for winters applications. The THV of fabrics for winter suiting is higher than summer suiting. 


\section{SOURCES OF FUNDING}

None.

\section{CONFLICT OF INTEREST}

None.

\section{ACKNOWLEDGMENT}

None.

\section{REFERENCES}

[1] Baghaei B, Shanbeh M, Ghareaghaji AA. Effect of tensile fatigue cyclic loads on bagging deformation of elastic woven fabrics. Indian J Fibre Text Res 2010; 35:298-302.

[2] Mourad MM, Elshakankery MH, Almetwally AA. Physical and stretch properties of woven cotton fabrics containing different rates of spandex. J Am Sci 2012; 8:567-72.

[3] Gersak J, Sajn D, Vili B. A study of the relaxation phenomena in the fabrics containing elastane yarns. Int J Cloth Sci Technol 2005; 17:188-99. doi:10.1108/09556220510590885.

[4] Ozdil N. Stretch and bagging properties of denim fabrics containing different rates of elastane. FIBRES Text East Eur 2008; 16:63-7.

[5] Qadir B, Hussain T, Malik M. Effect of elastane denier and draft ratio of core-spun cotton weft yarns on the mechanical properties of woven fabrics. J Eng Fiber Fabr 2014; 9:23-31.

[6] El-Ghezal S, Babay A, Dhouib S, Cheikhrouhou M. Study of the impact of elastane's ratio and finishing process on the mechanical properties of stretch denim. J Text Inst 2009;100, NO. 3:245-53. doi:10.1080/00405000701757925.

[7] AL-ansary MAR. Effect of spandex ratio on the properties of woven fabrics made of cotton / spandex spun yarns. J Am Sci 2011; 7:63-7.

[8] Choudhary A, Bansal S. Influences of elastane content, aesthetic finishes and fabric weight on mechanical and comfort properties of denim fabrics. J Text Eng Fash Technol 2018; 4:36-42. doi:10.15406/jteft.2018.04.00119.

[9] Ertaş OG, Ünal BZ, Çelik N. Analyzing the effect of the elastane-containing dual-core weft yarn density on the denim fabric performance properties. J Text Inst 2016; 107:116-26. doi:10.1080/00405000.2015.1016319.

[10] Subramanian S, Phalgumani GR, Manjunatha BR, Sitaram MS, Shringarpure AW, Bhatt IG. Assessment of crease recovery values of textile fabrics by different instruments 1983; 8:16-22.

[11] Majumdar A, Pol SB. Low stress mechanical properties of fabrics woven from bamboo viscose blended yarns. Fibers Polym 2014; 15:1985-91. doi:10.1007/s12221-014-1985-y.

[12] Gorjanc DS, Bizjak M. Impact of Pre-Finishing Process on Comfort Characteristics of Stretchable Cotton Fabric. J Eng Fiber Fabr 2015; 10:57-68.

[13] Kan CW, Yuen CWM. Evaluation of the performance of stretch denim fabric under the effect of repeated home laundering processes. Int J Fash Des Technol Educ 2009;2, No. 2-3:71-9. doi:10.1080/17543260903302329.

[14] Ploeg A Vander. 2016 AATCC International Conference Proceedings. Perform. Qual. Cott. denim Fabr. Comp. to blended stretch denim Fabr., 2016, p. 158-65. 